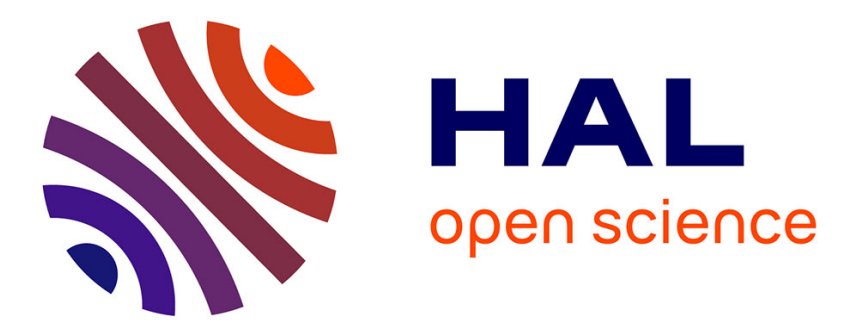

\title{
Erbium-doped yttria-stabilised zirconia thin films grown by pulsed laser deposition for photonic applications
}

\author{
A. Ruiz-Caridad, G. Marcaud, J.M. Ramirez, E. Durán-Valdeiglesias, C. \\ Lafforgue, J. Zhang, L. Largeau, T. Maroutian, S. Matzen, C. Alonso-Ramos, \\ et al.
}

\section{To cite this version:}

A. Ruiz-Caridad, G. Marcaud, J.M. Ramirez, E. Durán-Valdeiglesias, C. Lafforgue, et al.. Erbiumdoped yttria-stabilised zirconia thin films grown by pulsed laser deposition for photonic applications. Thin Solid Films, 2020, 693, pp.137706. 10.1016/j.tsf.2019.137706 . hal-02415781

\section{HAL Id: hal-02415781 \\ https://hal.science/hal-02415781}

Submitted on 4 Feb 2021

HAL is a multi-disciplinary open access archive for the deposit and dissemination of scientific research documents, whether they are published or not. The documents may come from teaching and research institutions in France or abroad, or from public or private research centers.
L'archive ouverte pluridisciplinaire HAL, est destinée au dépôt et à la diffusion de documents scientifiques de niveau recherche, publiés ou non, émanant des établissements d'enseignement et de recherche français ou étrangers, des laboratoires publics ou privés. 


\title{
Erbium-doped yttria-stabilised zirconia thin films grown by PLD for photonic applications.
}

\author{
A. Ruiz-Caridad ${ }^{a}$, G. Marcaud ${ }^{a}$, J. M. Ramirez ${ }^{b}$, Elena Durán-Valdeiglesias ${ }^{a}$, Christian Lafforgue ${ }^{a}$,

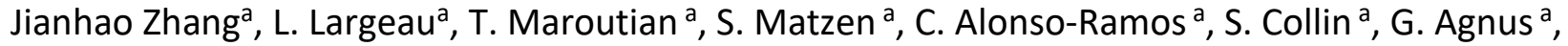 \\ S. Guerber ${ }^{a, c}$, C. Baudot ${ }^{c}$, F. Boeuf ${ }^{c}$, Stéphane Monfray ${ }^{c}$, Sébastien Crémer ${ }^{c}$, V. Vakarin ${ }^{d}$, E. \\ Cassan $^{\text {a }}$, D. Marris-Morini ${ }^{\text {a }}$, P. Lecoeur ${ }^{\text {, }}$, L. Vivien ${ }^{\text {a }}$.
}

${ }^{a}$ Centre de Nanosciences et Nanotechnologies (C2N), Université Paris-Saclay, CNRS UMR 9001, Palaiseau, 91120, France.

${ }^{b}$ III-V lab, a joint lab from Nokia Bell Labs, Thales and CEA, 1 avenue Augustin Fresnel, 91767 Palaiseau Cedex, France

'TR\&D STMicroelectronics SAS, Crolles, 38920 France

${ }^{\mathrm{d} I m e c}$, Kapeldreef, 3001, Leuven, Belgium

Email: alicia.ruiz-caridad@c2n.upsaclay.fr

\begin{abstract}
On-chip optical amplifiers operating at telecom wavelengths are crucial elements for signal recovering and routing in photonic integrated circuits. In this work, we present the optical and structural properties of Er-doped Yttria-Stabilized Zirconia (YSZ) thin films for the implementation of on-chip optical amplifiers in hybrid multifunctional photonic platforms. Photoluminescence excitation measurements have revealed strong luminescence at $1530 \mathrm{~nm}$ under $960 \mathrm{~nm}$ wavelength pumping, with lifetime values around $2 \mathrm{~ms}$ and a strong $\mathrm{Er}^{3+}-\mathrm{Er}^{3+}$ interaction for $\mathrm{Er}^{3+}$ doping concentrations beyond 1.5 atomic percentage (at.\%). This work contributes to establish the solid foundations for a new class of Er-doped on-chip amplifiers using the robust and stable YSZ host matrix.
\end{abstract}

\section{Introduction}

Silicon photonics is considered as a game-changing technology able to circumvent the microelectronics interconnection bottleneck. Furthermore, the need to efficiently manage nowadays' massive data traffic volumes has accelerated the search for multi-functional photonic integrated circuits able to adapt and reconfigure their optical properties in real-time conditions. In this regard, one of the most rewarding components is the integrated optical amplifier. This device could play a key role in the recovery of weak on-chip optical signals and routing. For that, advances on new materials engineering for hybrid integration on silicon platforms are the key to conquer limitations by adding other functionalities such more efficient electro-optic effects, enhanced nonlinearities or integrated on-chip laser to heterostructures [1-3]. For this purpose, functional oxides summon attention by its outstanding properties such as superconductivity, magnetism, ferroelectricity, catalytic activity, resistive switching, electro-optic effects, piezoelectricity, or optical nonlinearities [4-9]. One of the main challenges in hybrid integration platforms is lattice mismatch hindering epitaxial growth on silicon and introducing defects. Yttria-stabilized zirconia (YSZ) is a wellknown ceramic buffer layer for functional oxides such as PZT, $\mathrm{CoFe}_{2} \mathrm{O}_{4} \mathrm{LiNbO}_{3}, \mathrm{SrRuO}_{3}$ [10-13] with a lattice constant compatible with the one of silicon. YSZ thermal and chemical properties, hardness and mechanical durability makes this oxide a good candidate for photonic applications [14-16]. Moreover, it belongs to the mid-index contrast material family with promising optical properties [17]: low propagation loss [18], absence of two photon absorption 
(TPA), a large transparency window from the ultraviolet to the mid-infrared [19] and good Kerr effect [20] to name a few. Lasing on silicon remains one of the last missing elementary components of compact silicon-based photonics. In this regard, III-V materials, RE doping, quantum effects (Si quantum dots) or forcing direct bandgap recombination of excitons or hyper doping schemes levels in Ge [21-25] are some of the strategies used to obtain optical gain. Rareearth-doped functional oxides are active materials used for optical amplification due to their light enhancement properties with wavelengths within the optical communications range [26]. To avoid non-radiative radiation, low phononic materials are required to host rare-earth ions [27]. Optical amplification has been demonstrated in RE doped functional oxides as $\mathrm{LiNbO}_{3}, \mathrm{Al}_{2} \mathrm{O}_{3}$ or $\mathrm{Y}_{2} \mathrm{O}_{3}$ [28-31]. Moreover, doping introduces undesirable defects within the bulk crystalline matrix promoting optical losses within the material [32]. Another challenge whilst doping is to avoid ionion interaction that hinders luminescence and thus prevents from optical amplification. $\mathrm{Er}^{3+}$ ion transitions within the near-infrared (near-IR) wavelengths make this RE ion the perfect candidate for the development of efficient light emitting functional oxides at telecommunication wavelengths.

Recent studies demonstrated YSZ waveguides grown with propagation losses as low as $2 \mathrm{~dB} / \mathrm{cm}$ at a wavelength of $1380 \mathrm{~nm}$ [33] proving this oxide to be a good candidate for optical propagation. Therefore, in this paper, we study the crystallinity of variable concentration Er:YSZ thin films deposited by PLD on a c-cut sapphire substrate. Moreover, optimal $\mathrm{Er}^{3+}$ ion excitation at $960 \mathrm{~nm}$ wavelength is observed for emission in the near-IR. Luminescence efficiency and lifetime studies for different $\mathrm{Er}^{3+}$ concentrations have also been performed to find the optimal doping for a YSZ host.

\section{Experimental details}

Pulsed laser deposition (PLD) is a technique known to achieve high crystallinity in thin film oxides. In this regard, deposition of erbium-doped oxide thin layers grown by means of PLD was carried out in a high-vacuum stainlesssteel chamber. $\mathrm{KrF}$ excimer laser pumping at $248 \mathrm{~nm}$ wavelength, a fluence of $3 \mathrm{~J} / \mathrm{cm}^{2}$, and at $5 \mathrm{~Hz}$ repetition rate ablates a sintered erbium-doped YSZ target with an incident angle of $45^{\circ}$. Rotating sintered ceramic targets of variable percentage in erbium-doped $8 \mathrm{~mol} \%$ yttria-stabilized zirconia were placed at $50 \mathrm{~mm}$ from the substrate on a heated holder. Sapphire substrate was heated from room temperature to $800{ }^{\circ} \mathrm{C}$ at a rate of $10{ }^{\circ} \mathrm{C} / \mathrm{min}$ at an initial pressure of $10^{-6}$ Torr. The chamber receives a constant flux of oxygen at a pressure of $30 \mathrm{mTorr}$ during deposition. Thereafter, the sample is cooled under 300 Torr oxygen at a rate of $10^{\circ} \mathrm{C} / \mathrm{min}$. Variable angle spectroscopic ellipsometry (J.A. Woollam) analysed by a Kramers-Kronig consistent model was performed to extract the layer thickness and the refractive index of 2.15. Thin film structural analysis was performed by x-ray diffraction (XRD) using PANalytical $\mathrm{X}$ 'Pert Pro diffractometer in parallel beam configuration with monochromated $\mathrm{Cu} \mathrm{K} \alpha 1$ radiation (wavelength of 1.540 $598 \AA$ A). 


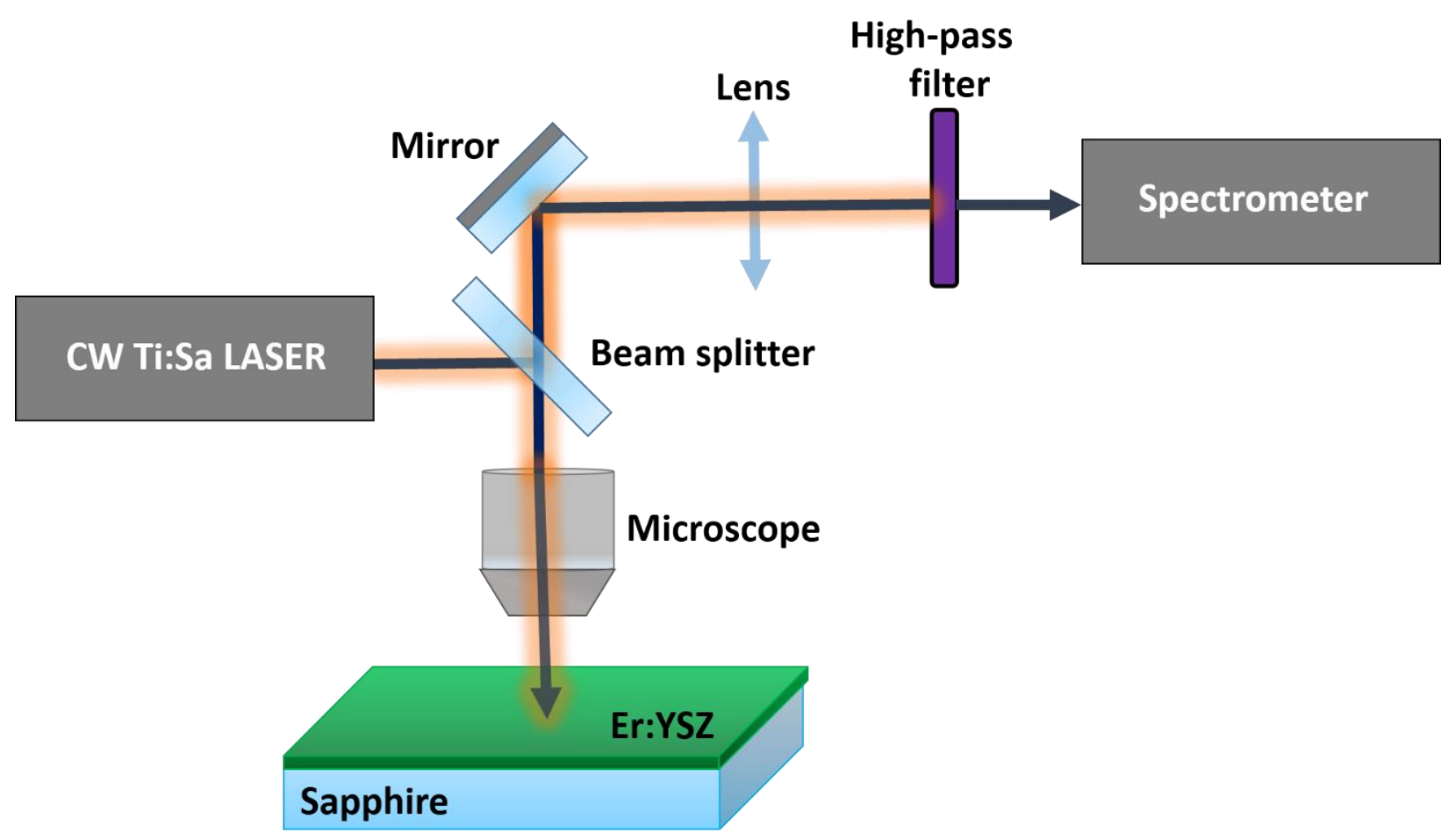

Fig. 1. (a) Scheme of ut-of-plane photoluminescence setup

Optical characterization of Er:YSZ thin films explores the luminescence of the $\mathrm{Er}^{3+}$ first excited state in the near IR as a function of the Er concentration within the YSZ matrix. Such inspection is interesting to identify the best tradeoff between quenching effects caused by $\mathrm{Er}^{3+}-\mathrm{Er}^{3+}$ interaction and the solubility of RE dopants in the crystalline YSZ matrix.

\subsection{Structural Characterization}

Erbium-doped YSZ (Er:YSZ) thin films were grown on a (0001) oriented sapphire substrate following two steps: i) annealing of the substrate and ii) deposition of Er:YSZ layer by PLD.
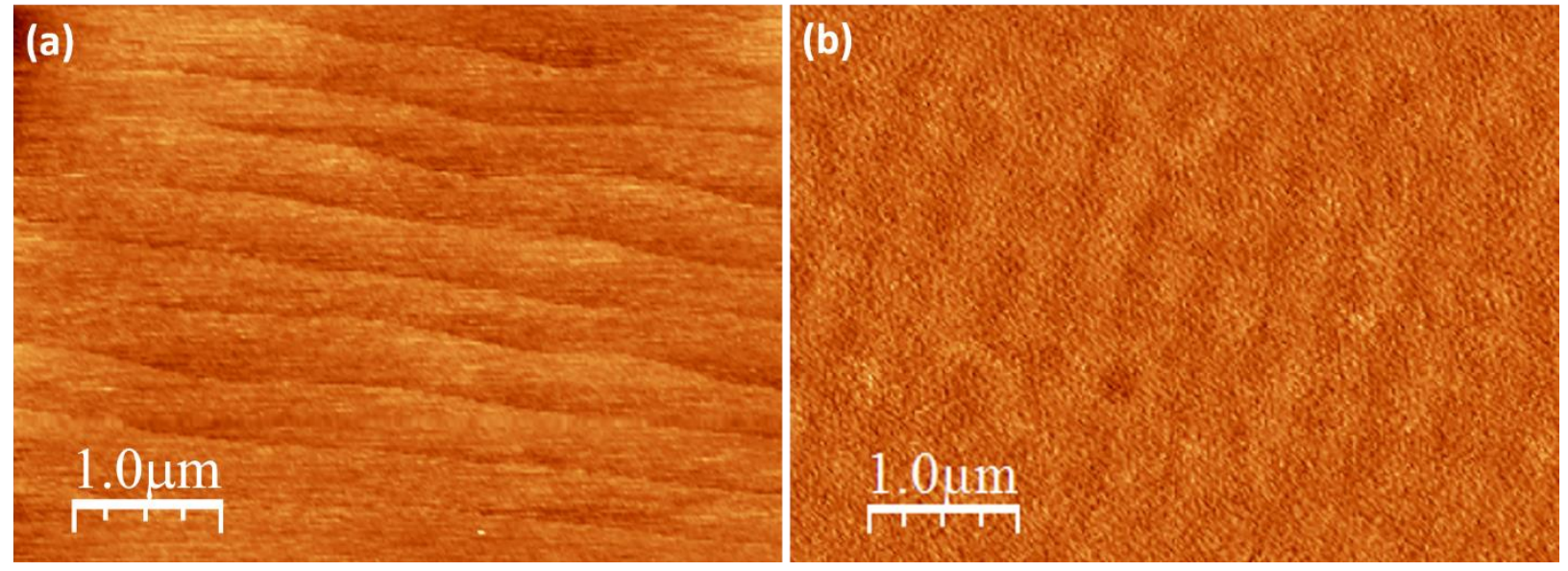
Fig. 2. AFM images of (a) sapphire substrate annealed surface and (b) thin film surface after PLD deposition.

First, we cleaned the sapphire substrate with a dissolution of acetone and ethanol at room temperature. Then, we annealed the sample at $1200{ }^{\circ} \mathrm{C}$ during $12 \mathrm{~h}$ under and pure oxygen atmosphere. In Fig. 2 (a), we observe by atomic force microscopy (AFM) an expected well-defined terrace-step structures characteristic of sapphire substrate annealed on an oxygen atmosphere [33]. AFM analysis of its surface proves an average height of $4 \AA$.

On a second step, we performed PLD to deposit $300 \mathrm{~nm}$ thick Er: YSZ thin films of variable erbium percentage under the same chamber conditions. After deposition, AFM (Fig. 2 (b)) was performed for all Er:YSZ sample surfaces, presenting all of them an average height of $20 \AA$. Such accentuation of the surface relief lies within the expected rugosity values.

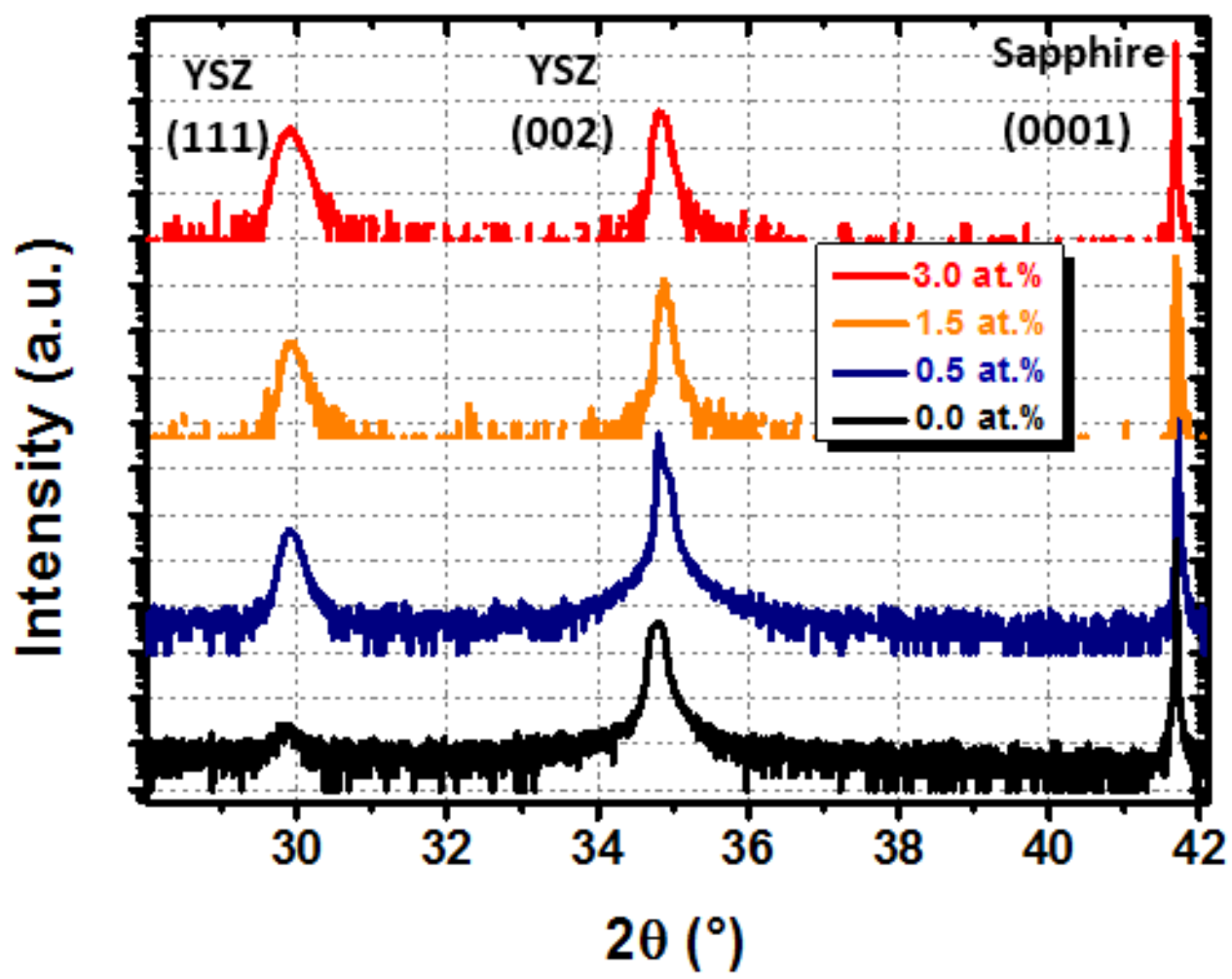

Fig. 3. (a) X-ray diffraction arranged from bottom to top in ascendant percentage of erbium doping YSZ (0, $0.5,1.5$ and $3 \%)$.

To structurally characterize Er:YSZ thin films and study its crystallinity we performed X-ray diffraction (XRD). In Fig. 3 we observe a diffraction peak common to all samples that corresponds to the (0001) sapphire orientation at $42^{\circ}$ [34]. A different peak attributed to the YSZ thin film (Figure 2) has been observed in the (002) direction, consistent with the study reported by Marcaud et al. [33] for YSZ thin films grown on oxygen-annealed sapphire substrates. Nevertheless, for Er:YSZ thin films, two growth orientations corresponding to the (111) and (002) directions at $29.8^{\circ}$ and $34.9^{\circ}$ respectively, are observed. It can be observed in Fig. 3 an increase in intensity of the diffracted peak corresponding to the (111) orientation with the increase of $\mathrm{Er}^{3+}$ concentration within the YSZ matrix.

\subsection{Optical Characterization}

\subsubsection{Photoluminescence emission}

Photoluminescence excitation (PLE), photoluminescence (PL) and optical power efficiency study were performed on a free-space optical bench using an out-of-plane scheme similar to the one shown in Fig. 1. Continuous wave Ti:Sapphire laser at variable wavelengths excites $\mathrm{Er}^{3+}$ ions perpendicular to the sample surface using a microscope with x50 magnification objective and numerical aperture of 0.55 . Emission and probe signals are perpendicularly 
collected by the same objective after $\mathrm{Er}^{3+}$ de-excitation and focused by a convergent lens of $50 \mathrm{~cm}$ focal plane from the detector. Laser wavelength is filtered with a high-pass filter $(1100 \mathrm{~nm})$ and only $\mathrm{Er}^{3+}$ emission in near-IR is detected on a iHR320 spectrometer with a nitrogen-cooled-detector.

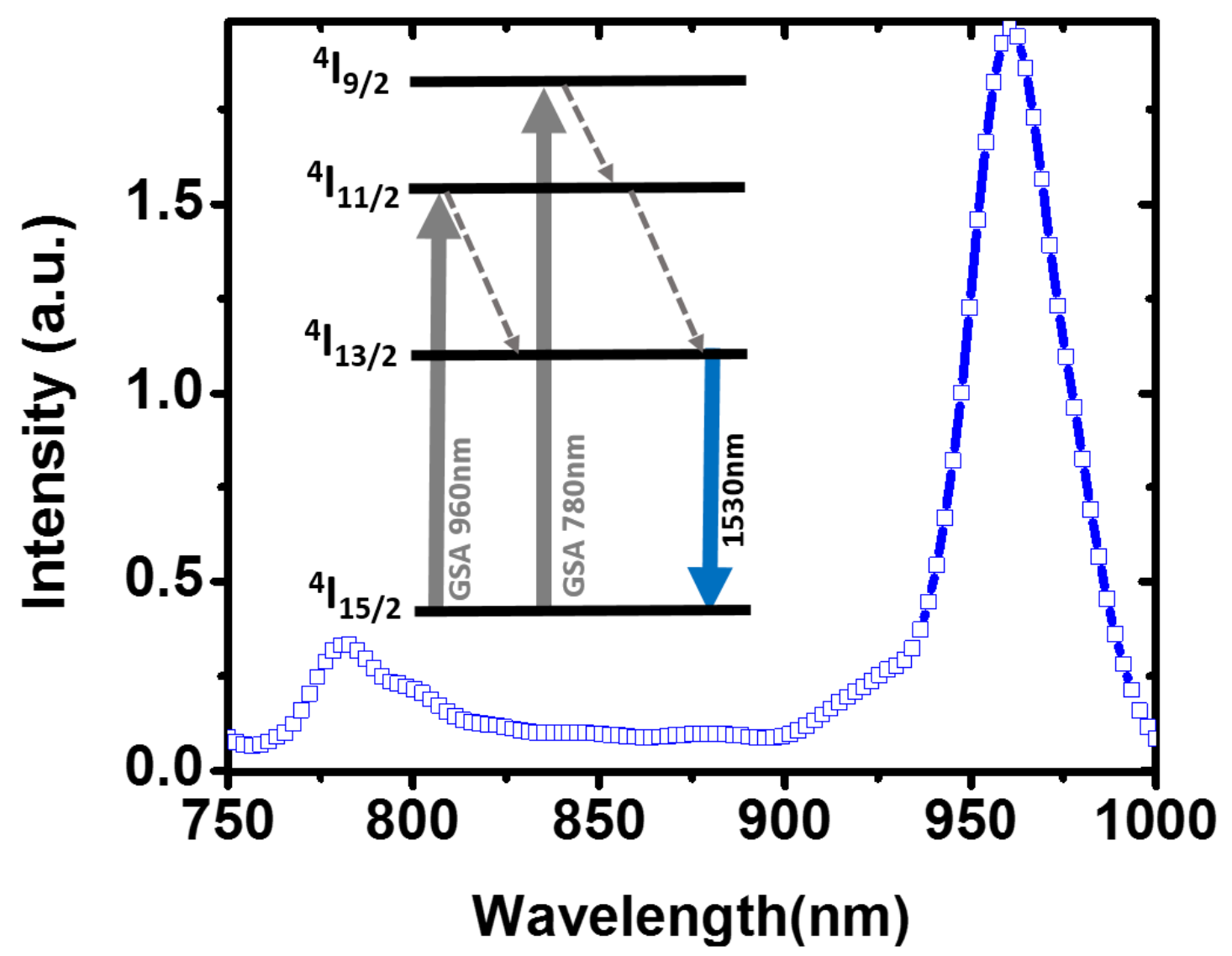

Fig. 4. PLE study of Er:YSZ thin film. Inset: scheme of ground state absorptions of $\mathrm{Er}^{3+}$-doped YSZ (grey arrows) and its emission in the near-IR (blue arrow).

Photoluminescence excitation (PLE) was performed to reveal optimal $\mathrm{Er}^{3+}$ ions excitation wavelengths for Er:YSZ thin film emission at $1530 \mathrm{~nm}$ corresponding to the ${ }^{4} \mathrm{I}_{13 / 2} \rightarrow{ }^{4} \mathrm{I}_{15 / 2}$ transition. Emission at $1530 \mathrm{~nm}$ is reached for excitation transitions ${ }^{4} \mathrm{I}_{15 / 2} \rightarrow{ }^{4} \mathrm{I}_{9 / 2}$ and ${ }^{4} \mathrm{I}_{15 / 2} \rightarrow{ }^{4} \mathrm{I}_{11 / 2}$ corresponding at around 800 and $980 \mathrm{~nm}$ wavelength due to its high absorption cross-section, decaying to the ${ }^{4} I_{13 / 2} \rightarrow{ }^{4} I_{15 / 2}$ transition [35,36]. Despite excitation transitions are characteristic of $\mathrm{Er}^{3+}$ ions, its correspondent energy level is host dependent [37]. Following the scheme of Fig 4, inplane PLE by Ti:Sapphire laser at $5 \mathrm{~mW}$ power and variable wavelength was carried out on Er:YSZ thin films. Intensity measurements for $1530 \mathrm{~nm}$ emission peak were recorded for excitation wavelengths between 750 and 1000 $\mathrm{nm}$. Therefore, in order to keep incident photon energy constant, pumping power of $5 \mathrm{~mW}$ has been adjusted for each wavelength. In Fig. 4, we observe two PLE maximum in intensity for all the Er: YSZ thin films: at $780 \mathrm{~nm}$ and 960 $\mathrm{nm}$ can be found a local and an absolute maximum corresponding to the ${ }^{4} \mathrm{I}_{15 / 2} \rightarrow{ }^{4} \mathrm{I}_{11 / 2}$ and ${ }^{4} \mathrm{I}_{15 / 2} \rightarrow{ }^{4} \mathrm{I}_{9 / 2}$ excitation transitions, respectively (Fig. 4 inset). Therefore, excitation of Er:YSZ thin films at $960 \mathrm{~nm}$ will give the most efficient emission at $1530 \mathrm{~nm}$.

\subsubsection{Photoluminescence}




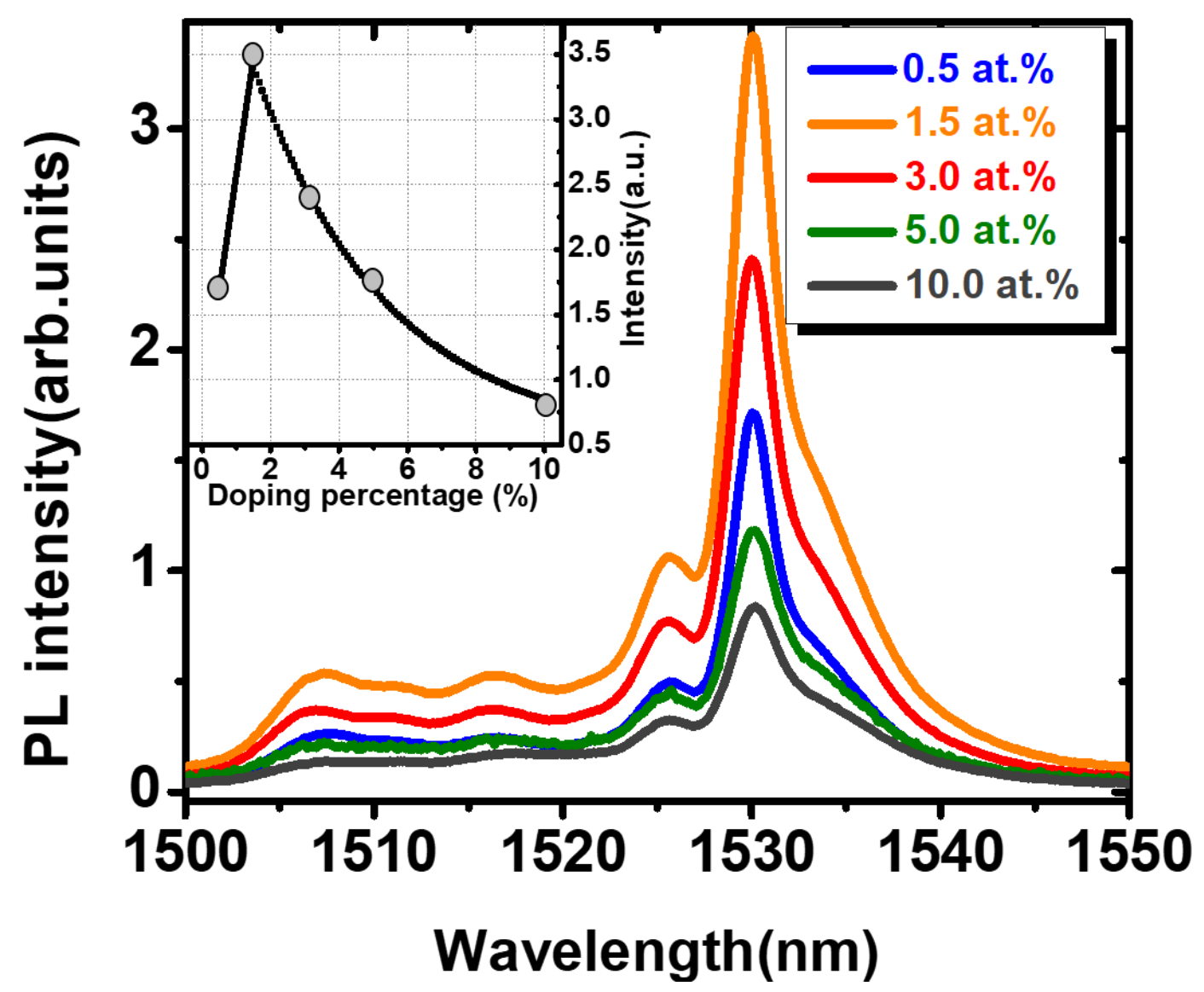

Fig. 5. $\mathrm{Er}^{3+}$ emission profile by PL for variable percentage of $\mathrm{Er}^{3+}$ ions. Inset, evolution of $\mathrm{Er}^{3+}$ maximum emission peak at $1530 \mathrm{~nm}$ with doping percentage.

Optimal excitation wavelength by PLE to excite $\mathrm{Er}^{3+}$ ions within a YSZ host was proved to be $960 \mathrm{~nm}$. Maximum of $\mathrm{Er}^{3+}$ emission is reached when increasing the number of $\mathrm{Er}^{3+}$ ions within the matrix whilst avoiding quenching effects by $\mathrm{Er}^{3+}-\mathrm{Er}^{3+}$ ion interaction. Therefore, we excited $\mathrm{Er}^{3+}$ doped YSZ thin layer at a $960 \mathrm{~nm}$ wavelength and $10 \mathrm{~mW}$ power for all samples to perform out-of-plane photoluminescence (PL) on an optical setup (Fig. 1). In Fig. 5, we observe the characteristic $\mathrm{Er}^{3+}$ emission profile for an increasing $\mathrm{Er}^{3+}$ concentration. Fig. 5 inset shows the evolution of maximum emission peak at $1530 \mathrm{~nm}$ with increasing doping concentration. Optimal trade-off between quenching effect and maximum RE doping concentration on YSZ thin film corresponds to a doping of 1.5 at $\%$. Therefore, hindering luminescence intensity with increasing doping can be observed in figure 4 inset, hence, 1.5 at $\%$ is the most effective doping concentration of $\mathrm{Er}^{3+}$ ions within the YSZ matrix in terms of near-IR luminescence. 


\subsubsection{Power efficiency}

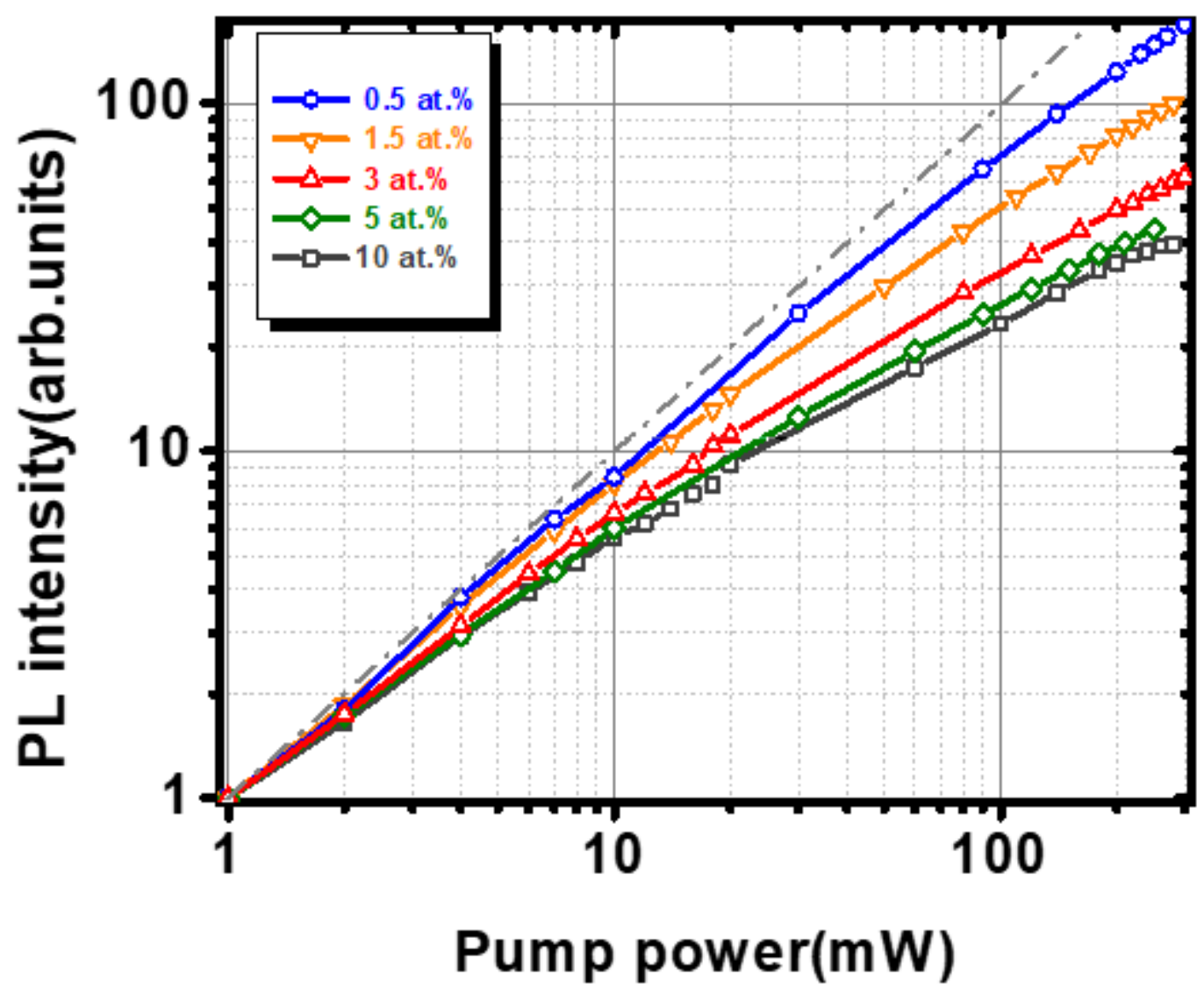

Fig. 6. (a) Log-log graphic of power study of Er:YSZ at $\mathrm{Er}^{3+}$ doping at different percentages.

Additionally, luminescence intensity can be enhanced by excitation of a higher number of $\mathrm{Er}^{3+}$ ions by increasing the laser pumping power. A decrease of the slope in the power efficiency is observed in fig. 6 under high pumping conditions, denoting the beginning of the saturation regime commonly observed when all optically active Er ions are excited in the matrix. For comparison, a grey dashed line with slope 1, reports the rate of $\mathrm{Er}^{3+}$ ions excited and radiatively emitted remaining constant, leading to no $\mathrm{Er}^{3+}-\mathrm{Er}^{3+}$ interaction. In Fig.6 it is shown in log-log scale the correspondence between increasing pumping power with the detected PL intensity for different doping percentages. At high pumping powers (around $140 \mathrm{~mW}$ ) saturation of PL intensity due to nonradiative decay of $\mathrm{Er}^{3+}$ ions by temperature quenching effects can be observed. Therefore, the most efficient concentration of $\mathrm{Er}^{3+}$ doping corresponds to 0.5 at $\%$ with a slope around 0.96 , followed by increasing doping percentages of 1.5, 3,5 and 10 at.\%. Moreover, saturation is shown for doping percentages higher than 3 at. $\%$ at around $140 \mathrm{~mW}$. This study reveals 0.5 at $\%$ doping to show low $\mathrm{Er}^{3+}-\mathrm{Er}^{3+}$ interaction which progressively increases with doping concentration.

\subsubsection{Lifetime}

Long lifetime of $\mathrm{Er}^{3+}$ excited state $\left({ }^{4} \mathrm{I}_{13 / 2}\right)$ is desired in order to reach population inversion for optical amplification purposes [38]. We have measured the decay curves of luminescence of three samples with different $\mathrm{Er}^{3+}$ concentration. Therefore, we performed direct excitation of the ${ }^{4} \mathrm{I}_{11 / 2}$ state by PL at room temperature. In Fig. 7, we can observe that lifetime of the state ${ }^{4} \mathrm{I} 1_{3 / 2}$ increase with increasing of erbium doping concentration. Lifetimes of 2.0, 1.6 and $1.2 \mathrm{~ms}$ 
were measured for Er:YSZ thin films with $\mathrm{Er}^{3+}$ concentrations of 3,1.5 and 0.5 at.\%, respectively. Accordingly, studies of Laversenne et al. proved a direct relation between increase of $\mathrm{Er}^{3+}$ concentration and increase of lifetime of ${ }^{4} \mathrm{I}_{13 / 2}$, consistent with our results [39].

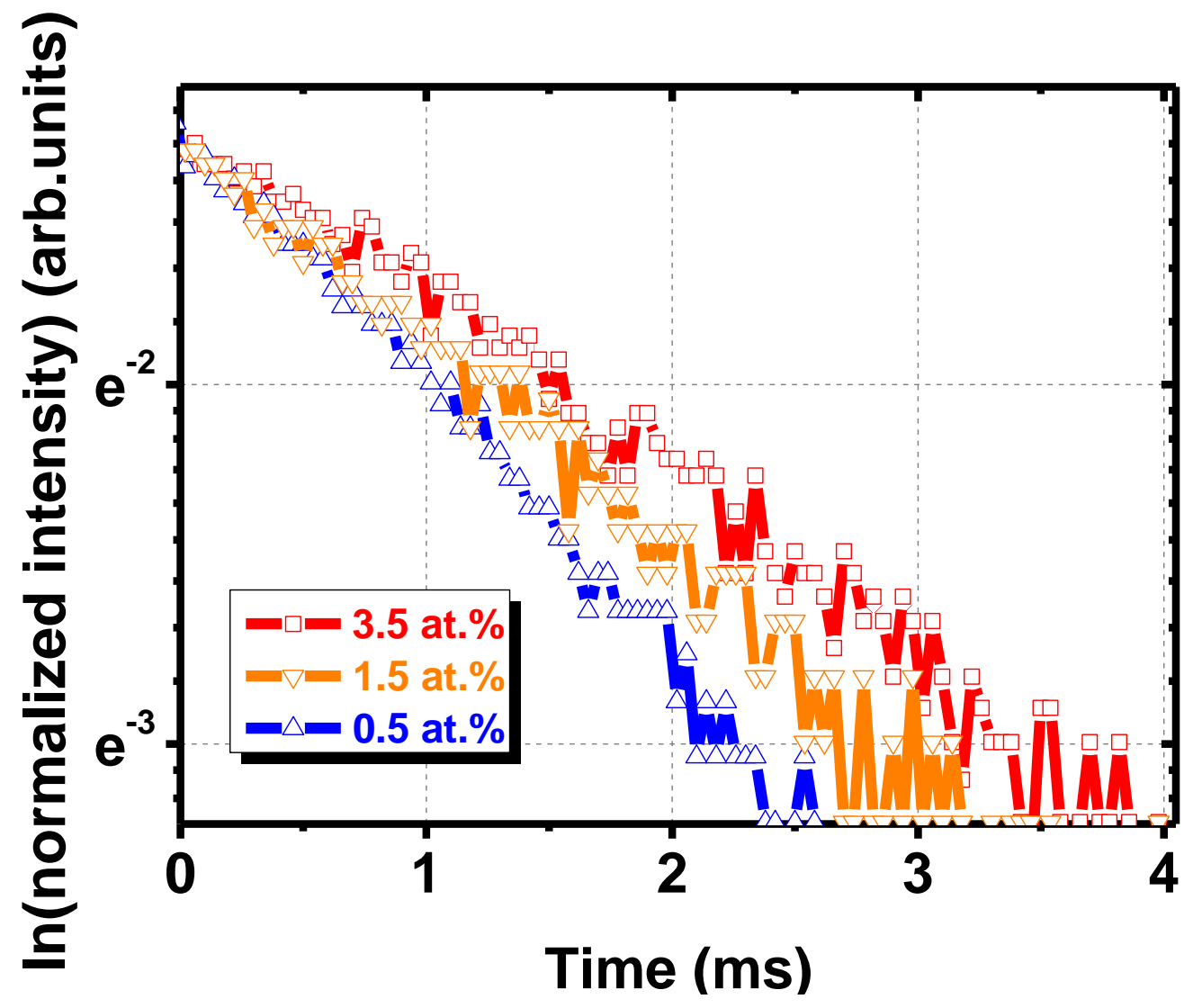

Fig. 7. Lifetime of out-of-plane Er:YSZ thin films for three different $\mathrm{Er}^{3+}$ concentrations.

\section{Conclusions}

In this study, we have grown 300nm thick Er:YSZ thin films with a refractive index of 2.15 on a sapphire substrate by PLD at different $\mathrm{Er}^{3+}$ concentrations. Structural characterization by AFM of the film surface, states a roughness as low as $2 \mathrm{~nm}$ for all the samples Furthermore, XRD proves two YSZ crystalline orientations. Whilst (002) refraction peak is observed for all the samples, an increase of (111) orientation is related to an increase of $\mathrm{Er}^{3+}$ concentration. In this regard, studies in the literature relate doping increase with bulk defaults and multiple crystal orientations.

PLE study for $1530 \mathrm{~nm}$ emission proves $780 \mathrm{~nm}$ and $960 \mathrm{~nm}$ to be the two excitation wavelengths corresponding to the $\mathrm{Er}^{3+}$ ions ${ }^{4} \mathrm{I}_{15 / 2} \rightarrow{ }^{4} \mathrm{I}_{9 / 2}$ and ${ }^{4} \mathrm{I}_{15 / 2} \rightarrow{ }^{4} \mathrm{I}_{11 / 2}$ transitions within YSZ crystal, respectively. Transition ${ }^{4} \mathrm{I}_{11 / 2}$ presents higher cross-section absorption, therefore, we fixed this excitation wavelength for PL, power efficiency, and lifetime studies. Results of PL proves emission for the ${ }^{4} \mathrm{I}_{13 / 2} \rightarrow{ }^{4} \mathrm{I}_{15 / 2}$ transition at $1530 \mathrm{~nm}$ for all $\mathrm{Er}^{3+}$ doping concentrations. While in PL measurements we can observe intensity emission within a bulk volume excited by the laser, power efficiency studies show a linear ratio between the pumping power and the emitted PL, which decreases for high pumping values. Such decrease of the power efficiency has been attributed to $\mathrm{Er}^{3+}-\mathrm{Er}^{3+}$ interaction due to highly $\mathrm{RE}$ doping concentrations. 
Therefore, despite observing higher PL emission at $1530 \mathrm{~nm}$ for 1.5 at. $\%$, it has been found for 0.5 at. $\% \mathrm{Er}^{3+}$ concentration to have higher power efficiency. Hence, while concentration of 0.5 at. \% proves higher excitationemission ratio, samples with a concentration of 1.5 at. \% have higher number of active $\mathrm{Er}^{3+}$ ions showing higher PL intensities. For concentrations higher than 1.5 at $\%, \mathrm{Er}^{3+}-\mathrm{Er}^{3+}$ interaction strongly hinders $\mathrm{Er}^{3+}$ emission by PL. Lifetime for three different $\mathrm{Er}^{3+}$ concentrations have been measured. As expected, higher $\mathrm{Er}^{3+}$ doped samples present higher lifetimes.

In this work, we have demonstrated efficient concentration of 1.5 at. $\% \mathrm{Er}^{3+}$ ions on YSZ thin films presents high lifetime and PL intensities. Increasing quenching effects are shown with increase of $\mathrm{Er}^{3+}$ ion concentration, hindering luminescence for concentrations higher than 1.5 at.\%.

\section{Acknowledgement}

This work has received the funding from the European Research Council (ERC) under the European Union's Horizon 2020 Research and Innovation Program (ERC POPSTAR) [grant number 647342] and ANR FOIST project.

\section{References}

[1] F. Eltes et al., "Monolithic integration of $\mathrm{Si} / \mathrm{BaTiO}_{3}$ electro-optic modulators on a silicon photonics platform," IEEPIEEE Photonics Conference (IPC), Reston, VA, 2018, pp. 1-2.

[2] B. Shen et al.,"Broadband couplers for hybrid silicon-chalcogenide glass photonic integrated circuits," Opt. Express, vol. 27, pp. 1378113792, Apr. 2019.

[3] E. Hosseini et al., "CMOS-compatible 75mW erbium-doped distributed feedback laser," Opt. Lett., vol. 39, pp. 3106-3109, May 2014.

[4] H.Y. Hwang, Y. Iwasa, M. Kawasaki, B. Keimer, N. Nagaosa and Y. Tokura,"Emergent phenomena at oxide interfaces," Nat. Mater., vol. 11, pp. 103-113, Jan. 2012.

[5] J. Heber, "Enter the oxides," Nature, vol. 459, pp. 28-30, May 2009.

[6] S. Kim, S.H. Choi and W. Lu," Comprehensive Physical Model of Dynamic Resistive Switching in an Oxide Memristor," ACS, Nano, vol. 8, no.3, pp. 2369-2376, Febr. 2014.

[7] M. Ando, K. Kadono, M. Haruta, T. Sakaguchi and M. Miya, "Large third-order optical nonlinearities in transition-metal oxides," Nature, vol. 374, pp. 625-627, Apr. 1995.

[8] M. Lorenz et al., "The 2016 oxide electronic materials and oxide interfaces roadmap", J. Phys. D, vol. 49, no.43, pp. 9-24, Oct. 2016.

[9] S. Abel et al., "A strong electro-optically active lead-free ferroelectric integrated on silicon", Nature Comm., vol. 4, p. 1671 , Apr. 2013.

[10] C. Jorel et al 2012 IOP Conf. Ser.: Mater. Sci. Eng. $41012012 \mathrm{R}$. Bachelet et al. ' $\mathrm{CoFe}_{2} \mathrm{O}_{4} /$ buffer layer ultrathin heterostructures on $\mathrm{Si}(001)$, Journal of Applied Physics 110, 086102 (2011)

[11] S. Hashiguchi, E. Min, K. Sakuta K. and T. Kobayashi," YBaCuO thin-film growth on electro-optic LiNbO3 substrate with buffer layer" Jpn. J. Appl. Phys., vol. 31, no. 1, pp. 780-785, Mar. 1992.

[12] Eom, C. B., et al. "Fabrication and properties of epitaxial ferroelectric heterostructures with (SrRuO3) isotropic metallic oxide electrodes." Applied Physics Letters 63.18 (1993): 2570-2572.J. Spišiak, M. Hartmanová, G.G. Knab and S. Krcho,"Thermal properties of yttriastabilized zirconia (YSZ)," J. Eur. Ceram. Soc., vol. 11, no. 6, pp. 509-514, Dec. 1993.

[13] T. Sakuma, Y.I. Yoshizawa, and H.J. Suto," The microstructure and mechanical properties of yttria-stabilized zirconia prepared by arcmelting," J.Mater. Sci., vol. 20, no. 7, pp. 2399-2407, Jul. 1985.

[14] J. Spišiak, M. Hartmanová, G.G. Knab and S. Krcho,"Thermal properties of yttria-stabilized zirconia (YSZ)," J. Eur. Ceram. Soc., vol. 11, no. 6, pp. 509-514, Dec. 1993.

[15] T. Sakuma, Y.I. Yoshizawa, and H.J. Suto," The microstructure and mechanical properties of yttria-stabilized zirconia prepared by arcmelting," J.Mater. Sci., vol. 20, no. 7, pp. 2399-2407, Jul. 1985.

[16] G.N. Morscher, P. Pirouz and A.H. Heuer, "Temperature dependence of hardness in yttria-stabilized zirconia single crystals," J. Am. Ceram. Soc., vol. 74, no. 3, pp. 491-500, Mar. 1991.

[17] L.C. Kimberling et al., "Monolithic Silicon Microphotonics", in Silicon Photonics edited by L. Pavesi, D.J. Lockwood (Springer Berlin Heidelberg New York, 2004), pp. 89-119.

[18] G. Castillo-Vega, E. Penilla, S. Camacho-López, G. Aguilar and J. Garay, "Waveguide-like structures written in transparent polycrystalline ceramics with an ultra-low fluence femtosecond laser," Opt. Mater. Express, vol. 2, pp. 1416-1424, Sep. 2012.

[19] H. Yamane and T. Hirai, "Yttria stabilized zirconia transparent films prepared by chemical vapor deposition," J. Cryst. Growth, vol. 94, no. 4, pp.880-884, Apr. 1989.

[20] R. Nakamura and Y. Kanematsu, "Femtosecond spectral snapshots based on electronic optical Kerr effect," Rev. Sci. Instrum., vol.75, no. 3, pp. 636-644, Mar. 2004.

[21] L. Pavesi, "Towards the first silicon laser," 2nd ed. vol. 93, Ed. Springer Science \& Business Media, 2003, pp. 331-383.

[22] G. T. Reed, G. Mashanovich, F. Y. Gardes and D. J., Thomson, "Silicon optical modulators," Nat. Photonics, vol. 4, pp. 518-526, Jul. 2010.

[23] L. Vivien et al., "42 GHz pin Germanium photodetector integrated in a silicon-on-insulator waveguide," Opt. express, vol. 17, no. 8, pp. 6252-6257, Apr. 2010

[24] E. J. Stanton, N. Volet and J. E. Bowers, "Low-loss demonstration and refined characterization of silicon arrayed waveguide gratings in the near-infrared," Opt. express, vol. 25, no. 24, pp. 30651-30663, Nov. 2017.

[25] J. Liu, X. Sun, R. Camacho-Aguilera, L. C. Kimerling and J. Michel, "Ge-on-Si laser operating at room temperature," Opt. let., vol. 35, no. 5, pp. 679-681, Mar.2010.

[26] Kenyon A.J., "Recent developments in rare-earth doped materials for optoelectronics" Prog. Quant. Electron., vol. 26, no. 4, pp. 225-284, Jan. 2002. 
[27] H. Lin, S. Tanabe, L. Lin, Y.Y. Hou, K. Liu, D.L. Yang, T.C. Ma, J.Y. Yu and E.Y.B. Pun, "Near-infrared emissions with widely different widths in two kinds of $\mathrm{Er}^{3+-}$ doped oxide glasses with high refractive indices and low phonon energies," J. Lumin., vol. 124, no. 1, pp. 167172, Jan. 2007.

[28] E. Lallier, "LiNbO3 with rare earths: lasers and amplifiers," in Proc. SPIE, vol. 1506, Micro-Optics II, ECO4 (The Hague '91), 1991, The Hague, Netherlands.

[29] P. Haro-González, L.L. Martin, I.R. Martin, G. Grazyna Dominiak-Dzik and W. Ryva-Romanowski," Pump and probe measurements of optical amplification at 584nm in dysprosium doped lithium niobate crystal",Opt. Mater. , vol. 33, pp.196-199, Dec. 2010.

[30] J.D. Bradley, R. Stoffer, L. Agazzi, F. Ay, K. Wörhoff and M. Pollnau, "Integrated $\mathrm{Al}_{2} \mathrm{O}_{3}: \mathrm{Er}^{3+}$ ring lasers on silicon with wide wavelength selectivity," Opt. Lett., vol. 35, pp. 73-75, Jan. 2010.

[31] J.D. Bradley, F. Ay, K. Wörhoff and M. Pollnau, "Fabrication of low-loss channel waveguides in $\mathrm{Al}_{2} \mathrm{O}_{3}$ and $\mathrm{Y}_{2} \mathrm{O}_{3}$ layers by inductively coupled plasma reactive ion etching" Appl. Phys., vol. 89, pp. 311-318, Dec. 2007.

[32] Tsur Y, Dunbar TD, Randall CA. Crystal and defect chemistry of rare earth cations in BaTiO3. Journal of Electroceramics. 2001 Oct 1;7(1):25-34.

[33] G. Marcaud et al.,"High-quality crystalline yttria-stabilized-zirconia thin layer for photonic applications," Phys. Rev. Materials, vol. 2, no. 3, p. 035202, Mar. 2018.

[34] Dai, J., Ong, H., \& Chang, R. (1999). Structural Properties of Yttria-stabilized Zirconia Thin Films Grown by Pulsed Laser Deposition. Journal of Materials Research, 14(4), 1329-1336. doi:10.1557/JMR.1999.0181

[35] E. Desurvire and J. R. Simpson, "Evaluation of ${ }^{4} \mathrm{I}_{15 / 2}$ and ${ }^{4} \mathrm{I}_{13 / 2}$ Stark-level energies in erbium-doped aluminosilicate glass fibers," Opt. Lett., vol. 15, pp. 547-549, May 1990.

[36] T. Wei et al., "Optical spectroscopy and population behavior between ${ }^{4} \mathrm{I} 11 / 2$ and ${ }^{4} \mathrm{I} 13 / 2$ levels of erbium doped germanate glass," Opt. Mater. Express, vol. 4, pp. 2150-2165, Sep. 2014.

[37] Mahran O, Shahat M, Hagar W. Comparative Studies of the Thulium and Erbium Doped from 1480-1650 nm with Different Host Materials as Optical Fiber Amplifiers. International Journal of Scientific \& Engineering Research. 2013;4(11):1815-20.

[38] Jambois O, Gourbilleau F, Kenyon AJ, Montserrat J, Rizk R, Garrido B. Towards population inversion of electrically pumped Er ions sensitized by Si nanoclusters. Optics express. $2010 \mathrm{Feb}$ 1;18(3):2230-5.

[39] Laversenne L, Goutaudier C, Guyot Y, Cohen-Adad MT, Boulon G. Growth of rare earth (RE) doped concentration gradient crystal fibers and analysis of dynamical processes of laser resonant transitions in RE-doped Y2O3 (RE= Yb3+, Er3+, Ho3+). Journal of alloys and compounds. 2002 Jul 17;341(1-2):214-9. 